\title{
Concrete containing thermoplastic waste as aggregates - the effect on the rebars' corrosion
}

\author{
S. Gavela, A. Ntziouni, E. Rakanta, N. Kouloumbi, \\ \& V. Kasselouri-Rigopoulou \\ School of Chemical Engineering, \\ National Technical University of Athens, Greece
}

\begin{abstract}
A lot of research has been performed on the utilization of waste products in concrete because it is widely used and has a long service life, which means that the waste is being removed from the waste stream for a long period. In the frame of an extended research program dealing with the utilization of thermoplastic waste, the effect on the reinforcement corrosion of concretes containing the above polymers as aggregates has been studied. As the amount of aggregates required in concrete is large, the environmental benefits are not only related to the safe disposal of the waste, but also to the environmental impacts arising from the extraction of aggregates, which include the visual intrusion and the loss of countryside. Three series of reinforced concrete specimens were prepared, one containing $12 \%$ by volume of aggregates high density polyethylene (HDPE), one containing $12 \%$ by volume of aggregates polypropylene (PP) and one without replacement of conventional aggregates. The specimens were cured in water for 7 days and then they were immersed in $3.5 \% \mathrm{wt} \mathrm{NaCl}$ solution. The following measurements were carried out in order to investigate if the corrosion behavior of the rebars is changed due to the replacement of the conventional aggregates by the thermoplastics: Potential versus time evolution, Linear Polarization, Electrochemical Impedance Spectroscopy, Carbonation Depth. Results showed that the replacement of conventional aggregates by the two polymers studied does not provoke rebars' corrosion.
\end{abstract}

Keywords: concrete, thermoplastic waste, aggregates, reinforcement corrosion, EIS, $L P R$. 


\section{Introduction}

Increasingly plastics become the material of choice by product designers because they provide useful properties as design flexibility and significant weight savings. For this reason the worldwide production has grown from virtually zero to almost 100 million tones per year in the last half century. Packaging is the main application for plastics with more than one third of the total. About $80 \%$ of polymer consumption corresponds to thermoplastics (mainly polyolefins, low density polyethylene, LDPE-19\%, polypropylene, PP-15\% high density polyethylene, HDPE-13\%), and the remaining to thermosets (mainly epoxy resins and polyurethans) [1]. Because disposal of post consumer plastics is increasingly being constrained by legislation, there is considerable demand for alternatives to disposal or landfilling.

In the frame of an extended research program, which deals with the utilization of thermoplastic waste in concrete, the use of two different thermoplastic polymers, high density polyethylene and polypropylene, has been studied, as a part of the conventional aggregates in concrete pavements with useful results [2, 3]. Generally, the replacement of a part of the conventional aggregates by a polymer results in reduction of strength (compressive and flexural) due to the lower strength of the polymers [2-4]. Also, the bond strength of the interface between the polymer and the mortar is relatively lower than the one between the conventional aggregates and the mortar [4].

In order to study the use of concrete containing thermoplastic wastes in reinforced concrete structures, the influence of the relatively lower bond strength of the interface between the polymer and the mortar should be examined. It should be noted that this lower bond strength probably would result in a higher porosity which could favour the corrosion of the reinforcement.

Plastics industry already uses a part from scrap mixed with virgin material in new production uses. But the volume of scrap resulting from the startup procedures or from the "out of specification products" is bigger than the scrap that can be used. For example, in some cases, as in film production, scrap can consist only $10 \%$. Additionally, recycling of scrap through melting restabilization has a high cost due to the high prices of incorporated stabilizers. On the other hand, the suggested use of polymers as aggregates in concrete has the advantage that sorting of different kinds of the polymer is not necessary. Nevertheless, a technoeconomical study will follow.

\section{Experimental procedure}

\subsection{Materials}

Concrete included in the research was prepared with cement type II 42.5, fine and coarse crushed limestone aggregates, plastic aggregates and tap water. The plastic aggregates used are industrial wastes from polypropylene (PP) and high density polyethylene (HDPE). The grain of the polymers did not vary widely and they were used as a replacement of the conventional fine aggregates. Cylindrical 
steel bars of type S500s/ELOT 971 with dimensions of $12 \mathrm{~mm}$ in diameter and 10 $\mathrm{mm}$ high and tap water were used for all test specimens. All specimens were prepared using a mixture of cement, water and aggregates with w/c ratio equal to 0.6. The chemical composition of steel is given in Table 1. A sieve analysis was performed on the gradation of the plastic as well as to the fine and coarse crushed limestone aggregates that were also used (Figure 2), according to ASTM C136.

Table 1: Chemical composition of steel rebars.

\begin{tabular}{|c|c|c|c|c|c|c|c|c|c|c|}
\hline & $\mathrm{C}$ & $\mathrm{Mn}$ & $\mathrm{S}$ & $\mathrm{P}$ & $\mathrm{Si}$ & $\mathrm{Ni}$ & $\mathrm{Cr}$ & $\mathrm{Cu}$ & $\mathrm{V}$ & $\mathrm{Mo}$ \\
\hline$\%$ & 0,22 & 1,24 & 0,044 & 0,032 & 0,28 & 0,10 & 0,10 & 0,52 & 0,075 & 0,028 \\
\hline
\end{tabular}

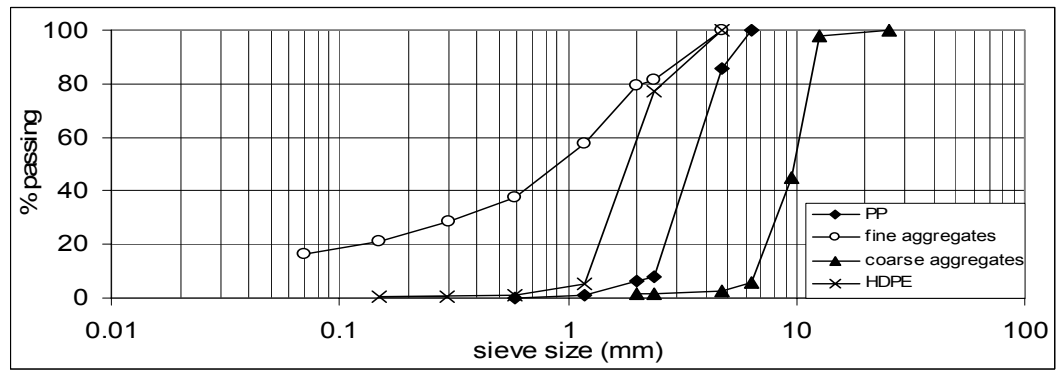

Figure 1: Gradation of plastic, fine and coarse aggregates.

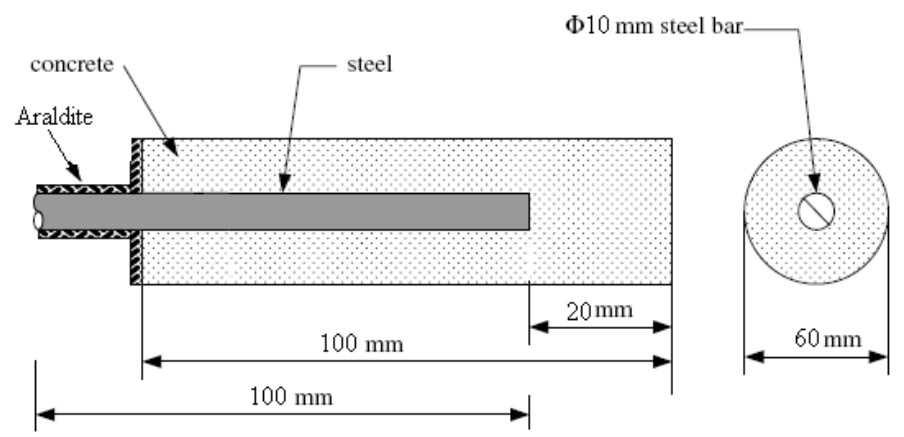

Figure 2: $\quad$ Schematic representation of cylindrical concrete specimen.

The results of the determination of specific gravity and water absorption of the aggregates are shown in Table 2. Three different mixes were made: one reference $\operatorname{mix}(0 \%$ by volume replacement of conventional aggregates), one mix containing PP aggregates $(12 \%$ by volume replacement of conventional aggregates) and one mix containing HDPE aggregates $(12 \%$ by volume replacement of conventional aggregates) (Table 3).

The concrete constituents were mixed in a concrete mixer for approximately 5 minutes, till a uniform consistency was achieved. The moulds $(100 \mathrm{~mm}$ in height 
Table 2: $\quad$ Physical properties of aggregates.

\begin{tabular}{|l|c|c|}
\hline Material & Specific gravity $\left(\mathrm{kg} / \mathrm{m}^{3}\right)$ & Water absorption (\%) \\
\hline Coarse aggregates & 2680 & 0.92 \\
\hline Fine aggregates & 2620 & 1.75 \\
\hline PP & 1020 & 0.00 \\
\hline HDPE & 910 & 0.00 \\
\hline
\end{tabular}

Table 3: $\quad$ Proportions for mixes containing PP.

\begin{tabular}{|l|c|c|c|}
\hline \multirow{2}{*}{ Mix component } & \multicolumn{3}{|c|}{ Volume replacement of conventional aggregates (\%) } \\
\cline { 2 - 4 } & $0 \%(\mathrm{RM})$ & $12 \%(\mathrm{PP} 12)$ & $12 \%(\mathrm{HDPE} 12)$ \\
\hline Water $\left(\mathrm{kg} / \mathrm{m}^{3}\right)$ & 205 & 205 & 205 \\
\hline Cement $\left(\mathrm{kg} / \mathrm{m}^{3}\right)$ & 350 & 350 & 350 \\
\hline Fine aggregates $\left(\mathrm{kg} / \mathrm{m}^{3}\right)$ & 876 & 666 & 666 \\
\hline Coarse aggregates $\left(\mathrm{kg} / \mathrm{m}^{3}\right)$ & 896 & 896 & 896 \\
\hline PP $\left(\mathrm{kg} / \mathrm{m}^{3}\right)$ & - & 86 & - \\
\hline HDPE $\left(\mathrm{kg} / \mathrm{m}^{3}\right)$ & - & - & 73 \\
\hline
\end{tabular}

and $60 \mathrm{~mm}$ in diameter) were filled with concrete and vibrated for consolidation using a vibrating table. Copper wire cables were connected to the steel bar for electrochemical measurements. Prior to the concrete specimens preparation, the steel rebar surface was cleaned according to the ISO/DIS 8407.3 [5, 6]. Thereafter, the rebars were placed axially in cylindrical moulds (Figure 3), where the concrete was cast and stored at ambient conditions in the laboratory for 24 hours. After being demolded, the specimens were placed in water for 7 days. Then the part of steel that is outside the concrete specimen was insulated with an epoxy resin, Araldite ${ }^{\circledR}$.

In order to examine the reinforcement corrosion due to the presence of chloride ions, reinforced concrete specimens were either vertically immersed to a depth of $3 \mathrm{~cm}$ (partial immersion) or completely immersed in $3.5 \%$ w.t $\mathrm{NaCl}$ solution in distilled water. Under these conditions only chloride induced corrosion occurred, since the high content of water impeded carbonation of the concrete. The experimental duration of this study was 90 days.

\subsection{Methods}

In this study, the following electrochemical techniques were performed on all reinforced concrete specimens, exposed to chloride environments, in order to study the corrosion process induced by chloride ion and the effect of the replacement of conventional aggregates by HDPE and PP.

a) Monitoring of Half-cell potential versus time: The half-cell potential of steel in the corrosive environment was periodically measured versus a saturated calomel electrode (SCE) using a high impedance voltmeter (10M $\Omega$ ).

b) Linear polarization measurements (LPR): The test setup included a EG\&G Model 263 Potensiostat/Galvanostat. Softcorr III developed by EG\&G Princeton 
Research was used for applying the potential scan and analyzing the parameters $I_{\text {corr }}, R_{p}$. A conventional three electrode cell was used with a counter electrode of two graphite rods and a SCE as a reference electrode. The corrosion medium used was a $3.5 \%$ w.t $\mathrm{NaCl}$ solution, and the scan rate $0,2 \mathrm{mV} / \mathrm{s}$.

c) Electrochemical impedance spectroscopy (EIS): EIS measurements were made with a three - electrode system using a 1286 Solatron Electrochemical Interface, in the frequency range between $10 \mathrm{kHz}$ and $10 \mathrm{mHz}$. Sinusoidal voltage of $15 \mathrm{mV}$ was applied. All the experiments were performed using the same arrangements in order to minimize errors induced by geometry and thus to allow the comparison of results. "Zplot" and "Zview" software was used for running experiments and fitting the curves with equivalent electrical circuits.

d) Carbonation depth: Carbonation depth was measured in various exposure time intervals by spraying on a freshly broken surface with $1 \%$ of phenolphthalein in a solution of $70 \%$ ethyl alcohol according to RILEM TC14CPC.

\section{Results and discussion}

\subsection{Half cell potential measurements}

Half - cell potential measurements of steel rebars is the most typical procedure to the routine inspection of reinforced concrete structures regarding the corrosion trend of the samples. Its use and interpretation are described in the ASTM C876 standard Test Method for Half - Cell Potential of Reinforcing Steel in Concrete. Potential readings, however, are not sufficient as criterion, since they are affected by number of factors, which include polarization by limited diffusion of oxygen, concrete porosity and the presence of highly resistive layer. According to ASTM C 876, potentials more negative than $-350 \mathrm{mV}$, with respect to SCE, indicate greater than $90 \%$ probability of active reinforcement corrosion. Values less negative than $-200 \mathrm{mV}$ SCE indicate a probability of corrosion below $5 \%$, while those falling between -200 and $-350 \mathrm{mV} \mathrm{SCE}$ indicate uncertainty of corrosion $[7,8]$.

The Half Cell potential measurements for steel rebars embedded in concrete specimens with different type of polymer aggregates, completely immersed in $3.5 \%$ w.t $\mathrm{NaCl}$, is presented in Figure $3 \mathrm{a}$ from where it is clear that the potential decay seemed to be independent of concrete composition. In general, the potential readings were characterized by a passive $(>-350 \mathrm{mV})$ and an active range, $-470<\mathrm{E}<-350 \mathrm{mV}$. In the case of $12 \%$ HDPE replacement the shift of potential towards negative direction crossing the threshold of $-350 \mathrm{mV}$ was observed in 18 days of immersion, whereas in $12 \%$ PP replacement it was reached in 8 days, and in case of conventional concrete RM threshold value of $-350 \mathrm{mV}$ vs. SCE is reached at approximately 25 days of complete immersion.

Time evolution of the half-cell potentials of the partially immersed in $3.5 \%$ wt. $\mathrm{NaCl}$ concrete specimens are shown in Figure 3b. From this figure it is observed that, all the categories of reinforced concrete specimens have shown less negative potential than $-250 \mathrm{mV}$ even up to 90 days of exposure indicating 
thus a passive condition of rebars. This behaviour is different from the complete immersion, probably because of the presence of oxygen, and not of other effects related with instability of the oxide film or oxygen diffusion polarization, as can be observed under complete immersion.
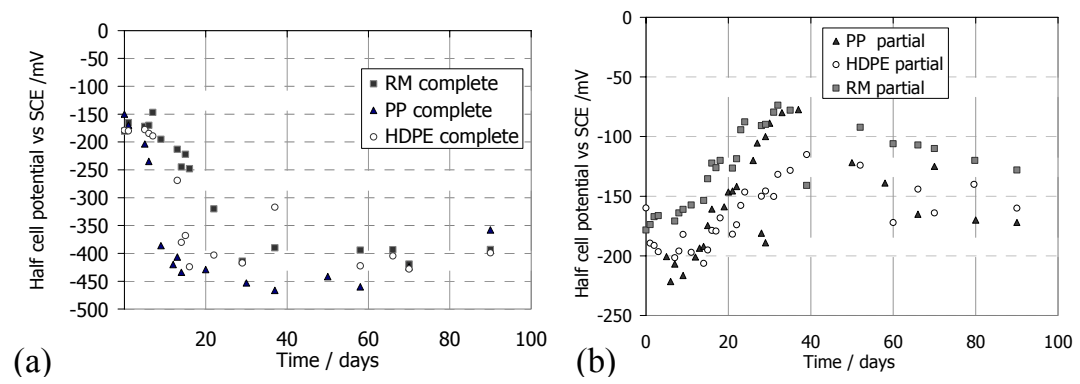

Figure 3: Half-cell potential measurements versus time in concrete specimens (a) completely and (b) partially immersed in a 3.5\% $\mathrm{NaCl}$ solution.

\subsection{LPR measurements}

The corrosion current density was measured using the DC linear polarization resistance method. The resistance to polarization ( $\mathrm{Rp}$ ) was determined by conducting a linear polarization scan in the range of $\pm 20 \mathrm{mV}$ of the open circuit potential and the corrosion current density (Icorr) was then calculated using the Stern-Geary equation $[9,10]$.

The corrosion level is considered negligible when $l_{\text {corr }}$ is less than $0.1 \mu \mathrm{A} / \mathrm{cm}^{2}$, while it is considered low in the range between 0.1 and $0.5 \mu \mathrm{A} / \mathrm{cm}^{2}$, and moderate and high for values superior to $1 \mu \mathrm{A} / \mathrm{cm}^{2}$ [11].

Table 4 shows the relative electrochemical results of $i_{\text {corr }}$ and corresponding $\mathrm{R}_{\mathrm{f}}$ values as well as of corrosion rate values, CR, for all the categories of concrete specimens, completely and partially immersed in $3.5 \% \mathrm{wt} \mathrm{NaCl}$ solution. The corrosion current density of steel reinforcement is presented in Figure 4. It is shown that the PP polymer concretes presented higher CR values and consequently lower $\mathrm{R}_{\mathrm{f}}$ than the conventional concrete, $\mathrm{RM}$, and the HDPE polymer concrete, till the end of the testing period (90 days). However these results show that the corrosion current density $i_{\text {corr }}$ for all the concrete specimens drops to the value of passive stage $\left(i_{c o r r}<0.1 \mu \mathrm{A} / \mathrm{cm}^{2}\right)$ both in the case of complete and partial immersion. This indicates that the presence of polymer aggregates does not worsen the corrosion behaviour of reinforced concrete. The differences between complete and partial immersion could be attributed to a rather stable oxide film produced in the later case.

\subsection{EIS measurements}

The Nyquist plot for all types of reinforced concrete specimens after 90 days of immersion in $3.5 \% \mathrm{wt} \mathrm{NaCl}$ solution is given in Figure 5. 
Table 4: $\quad$ Results of electrochemical measurements (LPR) of steel rebars in concrete specimens.

\begin{tabular}{|c|c|c|c|c|c|c|}
\hline \multicolumn{7}{|c|}{ Duration of specimens immersion: 16 days } \\
\hline & \multicolumn{2}{|c|}{$I_{\text {corr }} / \mu \mathrm{A} \cdot \mathrm{cm}^{-2}$} & \multicolumn{2}{|c|}{$R_{\mathrm{p}} / \mathrm{kOhms. \textrm {cm } ^ { - 2 }}$} & \multicolumn{2}{|c|}{$\mathrm{CR} \times 10^{-3} / \mathrm{mpy}$} \\
\hline $\mathrm{RM}$ & $\begin{array}{c}\text { Complete } \\
0.078\end{array}$ & $\begin{array}{c}\text { partial } \\
0.056\end{array}$ & $\begin{array}{c}\text { Complete } \\
0.293\end{array}$ & $\begin{array}{c}\text { partial } \\
0.399\end{array}$ & $\begin{array}{c}\text { Complete } \\
34.76\end{array}$ & $\begin{array}{c}\text { partial } \\
24.78\end{array}$ \\
\hline HDPE12 & 0.068 & 0.042 & 0.364 & 0.535 & 30.48 & 18.83 \\
\hline PP12 & 0.104 & 0.051 & 0.218 & 0.457 & 46.47 & 22.83 \\
\hline \multicolumn{7}{|c|}{ Duration of specimens immersion: 22 days } \\
\hline RM & 0.047 & 0.034 & 0.478 & 0.675 & 21.22 & 15.18 \\
\hline HDPE12 & 0.074 & 0.036 & 0.308 & 0.621 & 32.73 & 16.22 \\
\hline PP12 & 0.071 & 0.039 & 0.320 & 0.587 & 31.78 & 17.29 \\
\hline \multicolumn{7}{|c|}{ Duration of specimens immersion: 32 days } \\
\hline RM & 0.038 & 0.031 & 0.590 & 0.737 & 17.05 & 13.65 \\
\hline HDPE12 & 0.054 & 0.035 & 0.417 & 0.651 & 24.13 & 15.58 \\
\hline PP12 & 0.075 & 0.030 & 0.302 & 0.767 & 33.28 & 13.17 \\
\hline \multicolumn{7}{|c|}{ Duration of specimens immersion: 38 days } \\
\hline RM & 0.039 & 0.031 & 0.580 & 0.769 & 17.36 & 13.76 \\
\hline HDPE12 & 0.059 & 0.037 & 0.381 & 0.618 & 26.39 & 16.4 \\
\hline PP12 & 0.065 & 0.033 & 0.346 & 0.767 & 29.07 & 13.17 \\
\hline \multicolumn{7}{|c|}{ Duration of specimens immersion: 59 days } \\
\hline RM & 0.038 & 0.034 & 0.594 & 0.676 & 16.95 & 15.11 \\
\hline HDPE12 & 0.049 & 0.032 & 0.458 & 0.709 & 21.96 & 14.22 \\
\hline PP12 & 0.054 & 0.036 & 0.416 & 0.638 & 29.07 & 16.05 \\
\hline \multicolumn{7}{|c|}{ Duration of specimens immersion: 90 days } \\
\hline RM & 0.034 & 0.029 & 0.655 & 0.773 & 15.36 & 13.02 \\
\hline HDPE12 & 0.044 & 0.030 & 0.517 & 0.756 & 19.45 & 13.3 \\
\hline PP12 & 0.057 & 0.040 & 0.395 & 0.561 & 25.48 & 17.93 \\
\hline
\end{tabular}

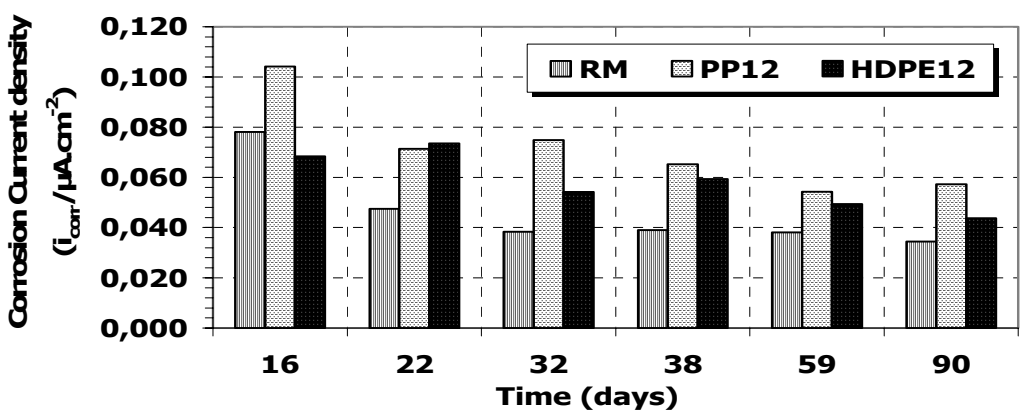

Figure 4: Corrosion current density $i_{\text {corr }}$ of reinforced concrete specimens versus experimental duration time, of complete immersion in $3.5 \%$ wt $\mathrm{NaCl}$ solution.

In the whole range of frequencies it is observed that the semicircle of the Nyquist plot is not completed resulting to a capacitive behaviour which indicates a situation of passivity for all the categories of specimens. At this stage corrosion 
resistance was independent of the type of aggregates used even after 90 days of immersion of corrosive environment.
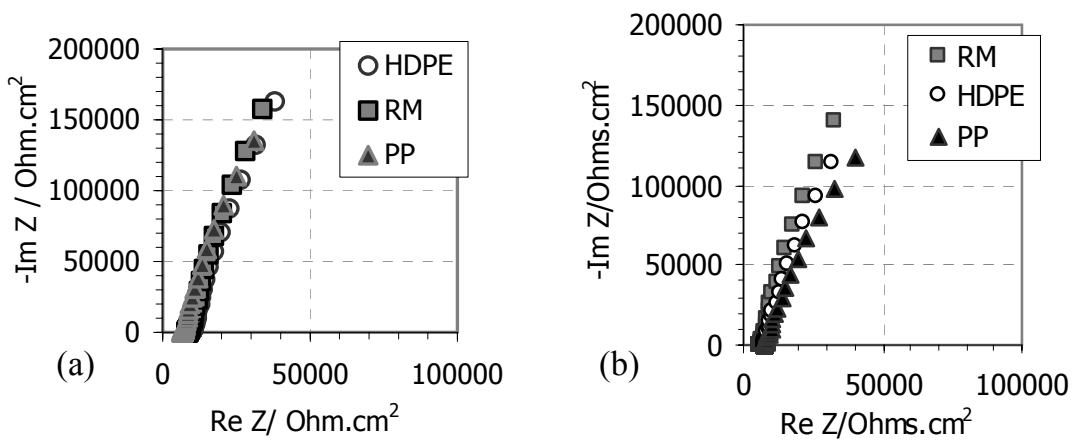

Figure 5: Nyquist plots for concrete specimens (a) partially and (b) fully immersed in $3.5 \%$ w.t $\mathrm{NaCl}$ solution, after 90 days.

In the case of passive stage the characteristics of the reinforced specimens were evaluated though the fitting of the experimental results to an equivalent circuit shown in Figure 6a. This circuit comprises a series of resistance Rs which accounts for the ionic conduction in the electrolyte filling the pores of concrete, a constant phase element $\mathrm{CPE}$, and $\mathrm{R}_{\mathrm{f}}$ which accounts for the capacitance of the passive film. The CPE is expressed by the following impedance relationship [12]: $\mathrm{Z}(\omega)=\mathrm{Y}_{0}{ }^{-1}(\mathrm{j} \omega)^{\mathrm{n}}$, where $\mathrm{Y}_{0}$ is a constant adjustable parameter used in non linear squares fitting, $\omega$ is the angular frequency and $n$ is a measure of arc depression defined as CPE power. For $n=0$, the impedance reduces to a resistor with the value of $\mathrm{Y}_{0}{ }^{-1}$, and for $\mathrm{n}=1$, the impedance reduces to a capacitor with a value of $Y_{0}$. For values of $n$ approaching 1 , it is common practice to use the $Y_{0}$ value as an approximation for capacitance [13]. The CPE are widely used in data fitting in order to simulate the heterogeneity of the structure or the distribution of the relaxation times.

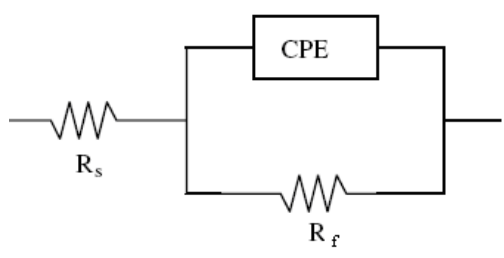

(a)

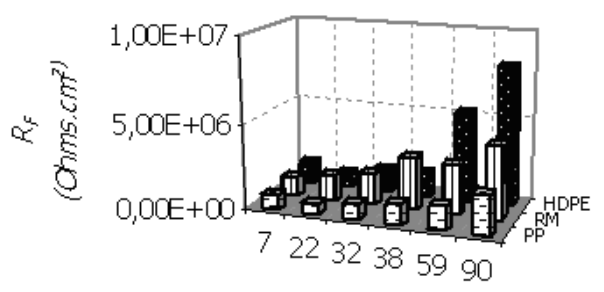

(b)

\section{Time (days)}

Figure 6: (a) Equivalent circuit used to fit the low frequency behaviour for passive steel in concrete, (b) evolution of $R_{f}$ versus time of steel rebars embedded in concrete specimens, completely immersed in $3.5 \%$ w.t $\mathrm{NaCl}$ solution. 
The results of $R_{f}-t$ (Figure $6 b$ ) show that the film resistance $R_{f}$, increases with time, which could be attributed to inhibition of corrosion activity on the steel surface, due to a passive film formation, resulting to a lowering with time of a corrosion current density of the reinforced steel bars as it is shown in Figure 4.

Correspondingly, the power of CPE, $n$, ranged between $0.88-0.92$ till the end of the testing period, for all the categories of reinforced concretes indicating a rather stable situation of the formed film.

\subsection{Carbonation depth}

No carbonation was observed in all specimens. Optical observation of the rebars after the removal of the concrete mass even at the 90 days duration of exposure did not show any pitting.

\section{Conclusions}

The results show that corrosion behaviour of reinforced concrete specimens is not practically influenced by the replacement of conventional aggregates by thermoplastic ones. All the categories of reinforced concrete specimens have shown more positive potential than $-250 \mathrm{mV}$ even up to 90 days of exposure indicating thus a passive condition of rebars. The corrosion current density $\mathrm{i}_{\text {corr }}$ for all the concrete specimens drops to the value of passive stage $\left(\mathrm{I}_{\text {corr }}<0.1\right.$ $\mu \mathrm{A} / \mathrm{cm}^{2}$ ). This is also validated by EIS measurements, which show that the film resistance increases with time. This increase could be attributed to inhibition of corrosion activity on the steel surface due to a passive film formation. From the above it is concluded that reinforced concretes containing thermoplastic aggregates can be safely used as it concerns their corrosion behaviour.

\section{Acknowledgements}

The project is co-funded by the European Social Fund (75\%) and National Resources (25\%) - EPEAEK II.

\section{References}

[1] Good Practices Guide on Waste Plastics Recycling - a guide by and for local and regional authorities. www.ecvm.org/img/db/ACRRReprot.pdf

[2] Gavela S., Kolias S., Kordatos C. \& Kasselouri-Rigopoulou V., A new approach of utilization of thermoplastic waste. Proceedings of the $1 \mathrm{st}$ Conference on Environmental Management, Planning and Economics (CEMEPE), Skiathos, Greece, 2007.

[3] Gavela S, Kolias S., Avramopoulou M. \& Kaselouri-Rigopoulou V., Investigation on the possibility of using concrete containing plastic waste as aggregates for pavement construction. Proceedings of the 10th International Symposium on Concrete Roads, Brussels, Belgium, 2006. 
[4] Gavela S., Hatzifoti C., Hatzifotis N., Kolias S. \& Kaselouri-Rigopoulou, V., Physiko - mechanical properties of concrete containing thermoplastic wastes as aggregates. Proceedings of 1st Hellenic Conference for the Utilization of By-products in Construction, Greece, 2005.

[5] Kouloumbi N., Batis G. \& Pantazopoulou P., Efficiency of natural greek pozzolan in chloride induced corrosion of steel reinforcement. Cement, Concrete and Aggregates, 17, pp. 18-25, 1995.

[6] Kouloumbi N., Batis G. \& Malami Ch., The anticorrosive effect of fly ash, slag and a greek pozzolan in reinforced concrete. Cement and Concrete Composites, 16, pp. 253-260, 1994.

[7] Pourbaix M. Atlas of Electrochemical Equilibria in Aqueous Solutions, NACE; p. 312, 1996.

[8] ASTM C 876-91, Standard test method for half-cell potential of reinforcing steel in concrete, Annual BOOK of ASTM Standards. ASTM international, West Conshohocken, PA 19428-2959, USA, 1991 reaproved 1999.

[9] Broomfield J.P., Corrosion of steel in concrete understanding, investigation and repair, E \& FN SPON, pp. 63-65,1997.

[10] Mansfeld F., An evaluation of polarization resistance measurements, Werkstoffe und Korrosion, Verlag Chemie, pp. 6-11, 1977.

[11] Millard S.G., Law D., Bungrey J.H. \& J. Cairns, Environmental influences on linear polarization corrosion rate measurements in reinforced concrete. NDT\&E International, 34, pp. 409-417, 2001.

[12] Jafar M.I., Dawson J.L. \& John D.G., Electrochemical Impedance and harmonic analysis measurements on steel in concrete, Electrochemical impedance: analysis and interpretation. ASTM Publication STP1188, J.R. Scully, D.C. Silverman, M.W. Kendding, Eds., American Society for Testing and Materials, Philadelphia, 1993.

[13] Andrade C, Soler L, Alonso C, Nóvoa R.X. \& Keddam M., The importance of geometrical considerations in the measurement of steel corrosion in concrete by means of AC impedance. Corrosion Science, 37, pp. 2013-23, 1995. 